Article

\title{
Fourfold Filtered Statistical/Computational Approach for the Identification of Imidazole Compounds as HO-1 Inhibitors from Natural Products
}

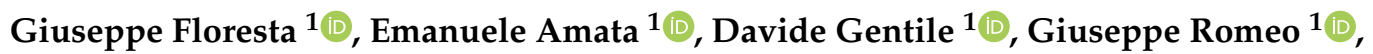 \\ Agostino Marrazzo ${ }^{1}\left(\mathbb{D}\right.$, Valeria Pittalà ${ }^{1} \mathbb{D}$, Loredana Salerno ${ }^{1, *}$ and Antonio Rescifina ${ }^{1,2, *(\mathbb{D})}$ \\ 1 Department of Drug Sciences, University of Catania, V.le A. Doria, 95125 Catania, Italy; \\ giuseppe.floresta@unict.it (G.F.); eamata@unict.it (E.A.); davide.gentile@studium.unict.it (D.G.); \\ gromeo@unict.it (G.R.); marrazzo@unict.it (A.M.); vpittala@unict.it (V.P.) \\ 2 Consorzio Interuniversitario Nazionale di ricerca in Metodologie e Processi Innovativi di \\ Sintesi (C.I.N.M.P.S.), Via E. Orabona, 4, 70125 Bari, Italy \\ * $\quad$ Correspondence: lsalerno@unict.it (L.S.); arescifina@unict.it (A.R.); Tel.: +39-095-738-5017 (A.R.)
}

Received: 16 January 2019; Accepted: 9 February 2019; Published: 12 February 2019

\begin{abstract}
Over-regulation of Heme oxygenase 1 (HO-1) has been recently identified in many types of human cancer, and in these cases, poor clinical outcomes are normally reported. Indeed, the inhibition of HO-1 is being considered as an anticancer approach. Imidazole scaffold is normally present in most of the classical HO-1 inhibitors and seems indispensable to the inhibitory activity due to its strong interaction with the Fe(II) of the heme group. In this paper, we searched for new potentially HO-1 inhibitors among three different databases: Marine Natural Products (MNP), ZINC Natural Products (ZNP) and Super Natural II (SN2). 484,527 compounds were retrieved from the databases and filtered through four statistical/computational filters (2D descriptors, 2D-QSAR pharmacophoric model, 3D-QSAR pharmacophoric model, and docking). Different imidazole-based compounds were suggested by our methodology to be potentially active in inhibiting the HO-1, and the results have been rationalized by the bioactivity of the filtered molecules reported in the literature.
\end{abstract}

Keywords: virtual screening; marine products database; natural products database; heme oxygenase; HO-1 inhibitors; imidazole

\section{Introduction}

Heme oxygenase, discovered back in the late sixties, is mostly acknowledged as a family of enzymes deputed to the catabolism of free circulating heme [1]. This reaction produces sole catabolites such as carbon monoxide (CO) and biliverdin (BV) further reduced to bilirubin (BR); both of them endowed with strong cytoprotective activities. It is only in the late eighties that two different isoforms of $\mathrm{HO}$ were recognized [2]. The inducible $\mathrm{HO}-1$ isoform (32 kDa protein) is the first characterized and recognized also as heat shock protein 32 (Hsp32). The second isoform is the constitutive HO-2 (36 kDa protein) that is ubiquitously expressed and with abundant levels in the brain and testes. The two proteins share an overall homology of $45 \%$ with a peak of $55 \%$ in the conserved core regions [3].

HO-1 is mostly expressed in the liver and spleen. In the presence of a diversity of noxious insults, mainly oxidative stress, HO-1 is highly up-regulated. HO-1 expression is mainly transcriptionally regulated by the nuclear factor (erythroid-derived 2)-like 2 (Nrf2), the nuclear factor kappa-light-chain-enhancer of activated B cells (NF- $k \mathrm{~B})$, and a variety of kinases including protein kinase C (PKC) [4,5]. A crucial role of HO-1 is also the cytoprotection and the preservation of homeostatic equilibrium by modulating inflammatory and antioxidant reactions, regulating cellular proliferation, apoptosis, and immune response. HO-1 overexpression exerts valuable 
protection in diseases such as lung and cardiovascular injuries, diabetes, metabolic diseases, and transplantation [6-10]. HO-1 induction can be regarded as an evolutionary mechanism of protection that overall safeguards cells and tissues against stressful conditions and stimulates cell-survival. These protective roles are exerted through the enhanced degradation of the pro-oxidant heme and the production of protective by-products $\mathrm{CO}, \mathrm{BV}$, and $\mathrm{BR}$ (Scheme 1). Nevertheless, it is unlikely that the $\mathrm{HO}$ enzymatic activity can mediate such a plethora of protective roles exclusively via its catabolites. Besides the well-known enzymatic activity, relevant signaling functions have been demonstrated for HO-1 and include redistribution of subcellular localization [11]. In fact, even though enzymatically active HO- 1 is mainly located in the endoplasmic reticulum, in a truncated and inactive form, $\mathrm{HO}-1$ can move into other compartments such as the nucleus, the caveolae, and the mitochondria [12-14]. Migration of HO-1 from the cytoplasm exerts important non-enzymatic signaling functions, resulting in the regulation of gene expression, modulation of protein translation, and activation of DNA repair proteins [11]. Nuclear HO-1 is able to prevent Nrf2 phosphorylation and related ubiquitin-mediated proteolysis, providing Nrf2 accumulation in the nucleus that in turn regulates HO-1 expression itself thus sparking the beginnings of a virtuous circle [15]. Thanks to its cytoprotective roles, HO-1 under physiological conditions inhibits the transition of normal cells to precancerous or malignant ones by preventing ROS-mediated carcinogenesis.

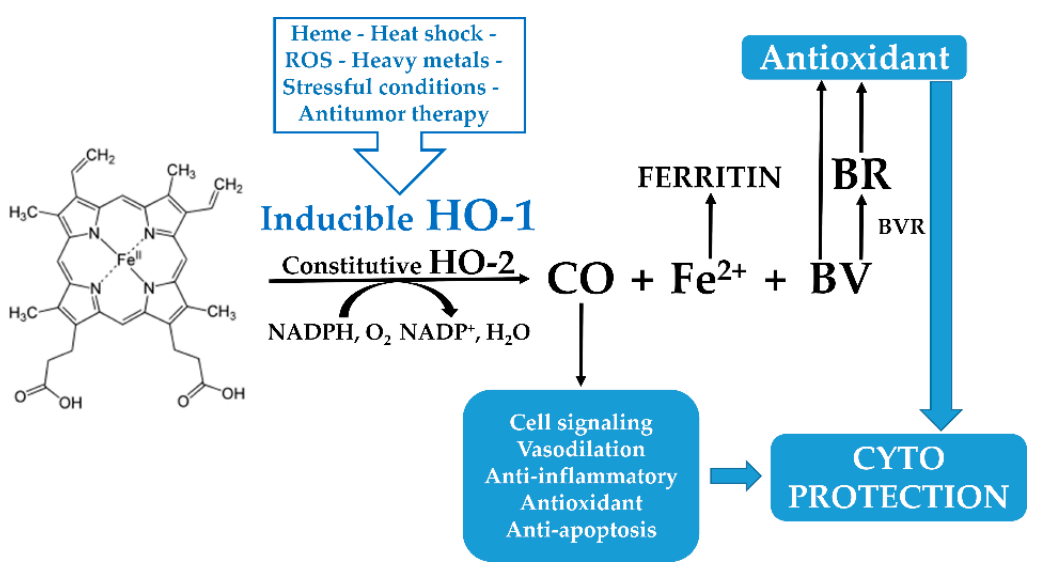

Scheme 1. Schematic representation of the heme degradative pathway catalyzed by the heme oxygenase system (HO). HO-2 is a constitutive enzyme, whereas $\mathrm{HO}-1$ is inducible by different noxious stimuli. Elimination of the pro-oxidant heme by both HOs involves cleavage of the protoporphyrin IX ring of heme with production of $\mathrm{CO}, \mathrm{Fe}^{2+}$, and biliverdin (BV). $\mathrm{BV}$ is converted by biliverdin reductase (BVR) into bilirubin (BR). Both $\mathrm{CO}$ and $\mathrm{BV}$ are bioactive molecules. The $\mathrm{Fe}^{2+}$ is then stored by the ferritin. All the products of heme catabolism are cytoprotective. However, overexpression of HO-1 (such as during antitumor therapy) may promote tumor growth and spreading.

Nevertheless, aberrant levels of HO-1 and Nrf2 have been well-documented in different types of human cancers [16-20]. In fact, by this overexpression, HO-1 could maintain a favorable redox balance in cancer cells by keeping ROS levels in a range that promotes their proliferation and survival, bypass apoptosis, giving rise to tumor growth, metastasis and chemoresistance. In the last decade, there have been dramatic increases in the number of papers that deal with the oncogenic involvement of the HO-1, and cancer patients with HO-1 aberrant overexpression seem to have lower survival rates and poor clinical outcomes. In this context, despite novel chemical inducers of HO-1 are useful in oxidative stress-based diseases [21,22], the identification of novel HO-1 selective inhibitors is of high interest in different types of cancers [23,24]. Other than metalloporphyrins, classical HO-1 inhibitors are characterized by an azole-based structure, with a preference towards a non-substituted imidazole ring, a central linker, and a hydrophobic portion of different size. The imidazole ring is ideal for activity and selectivity towards $\mathrm{HO}$ family with respect to other heme-containing enzymes and represents the first anchoring point of the molecule to the $\mathrm{Fe}^{2+}$ residue of heme when it is located inside $\mathrm{HO}-1$ 
heme binding pocket [25]. Specifically, imidazole ring of the inhibitor coordinates with the $\mathrm{Fe}^{2+}$ atom of heme substrate through the electron lone pair of nitrogen at the 3-position. This binding prevents the initiation of heme catabolism and results in non-competitive enzymatic inhibition.

Yet, as the imidazole moiety is generally acknowledged for its hepatotoxic activity, its substitution would be desirable [26]. However, any attempt of imidazole substitution performed until today afforded only poor results. The only accepted substitution is with a $1 H-1,2,4$ triazole or a $1 H$-tetrazole ring, but a reduction of the potency of the HO-1 inhibition is generally observed [27]. Consequently, the imidazole nucleus is currently the best choice to design novel HO- 1 inhibitors. The only one different scaffold that has been recently described, is present in a small series of quinoline-based imidazole derivatives [28]. Despite the presence of an imidazole nucleus, these molecules represent the only example of HO-1 inhibitors structurally and functionally different from classical imidazole-based HO-1 inhibitors. In fact, dissimilarly to the classical imidazole-based inhibitors, the imidazole ring is substituted at the 2-, 4-, and 5-positions, and these quinoline compounds behave as competitive inhibitors being able to displace the substrate from the catalytic site of the enzyme. More in-depth studies on this class of compounds are necessary to define their importance in the field of HO-1 inhibitors.

In silico studies represent a convenient and efficient avenue to the identification of new scaffolds and new bioactive compounds with significant savings of time and money. In agreement with our growing interest in developing selective and potent HO-1 inhibitor and driven by the need of identifying new scaffolds endowed with HO-1 activity and selectivity, we recently reported 2D- and 3D-QSAR models based on the whole collection of HO-1 and HO-2 inhibitors reported so far and collected in a database previously built by our research group (HemeOxDB, http:/ / www.researchdsf. unict.it/hemeoxdb) [29-34]. Also, scaffold hopping analysis allowed to design and synthesize new potent HO- 1 inhibitors characterized by a novel chemotype obtained by modifying the central region of the ligands [35].

As demonstrated, given that in silico studies enable the identification of new potent HO-1 inhibitors, in the present paper we report the virtual screening of an imidazole-based moiety fully enriched database obtained by the combination of the three different databases Marine Natural Products (MNP, 14,492 entries), ZINC Natural Products (ZNP, 144,766 entries) and Super Natural II (SN2, 325,319 entries). The entire process was conducted employing a fourfold statistical/computational filtration scheme (Scheme 2).

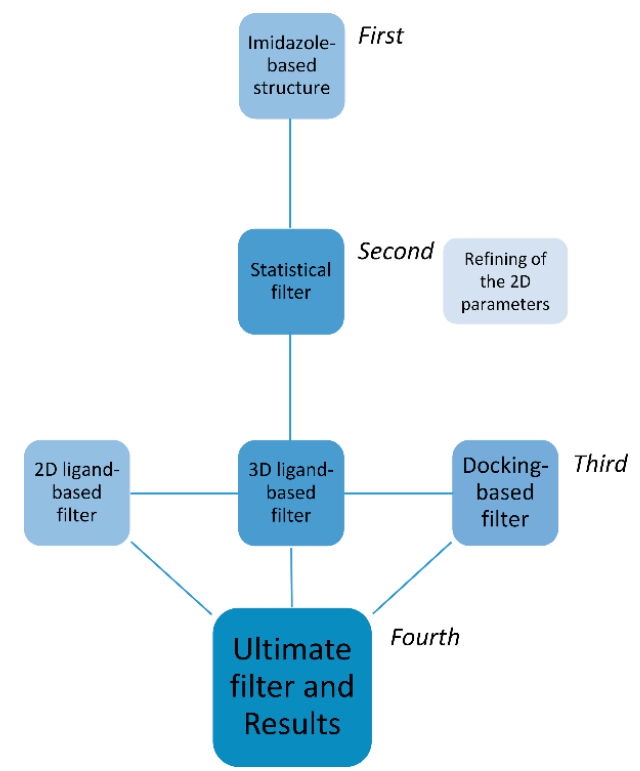

Scheme 2. Schematic representation of the used workflow. 


\section{Results}

\subsection{First, Second and Third Level of the Statistical/Computational Filtration}

The first and second filters used in the selection of compounds were a structural filter and a statistical (based on 2D descriptors) ones. Starting from the three different databases MNP, $\mathrm{ZNP}, \mathrm{SN} 2$, all the structures containing a non-fused 2-non-substituted imidazole ring were first retrieved, by the substructure filter present in DataWarrior software (5.0.0, Idorsia Pharmaceuticals Ltd, Allschwil, Switzerland) [36], for a total of 1,091 molecules. Then the molecules were filtered through a statistical/2D descriptors filters. To perform this, we analyzed the most potent and selective compounds present in the HemeOxDB [31] retrieving only the molecules presenting an $\mathrm{HO}-1 \mathrm{IC}_{50}$ value $\leq 10 \mu \mathrm{M}$ and an $\mathrm{HO}-1 / \mathrm{HO}-2$ selectivity $\geq 10$, for a total of 62 entities. The ranges of Molecular weight (200/535), cLogP (-0.35/5.4), cLogS (-5.90/-0.85), H-acceptors (2/8), H-donor (0/1), Druglikeness $(-13.20 / 8.2)$, DrugScore (0.12/0.96), Total Surface Area (164/390), Relative PSA (0.085/0.35), and Polar Surface Area (18/90) belonging to the 62 potent and selective compounds were all chosen as $2 \mathrm{D}$ descriptors and the dataset of 1,091 molecules was further filtered using these interval values to give eight molecules from the MNP, 47 from the ZNP and 89 from the SN2, for a total of 144 molecules (Supplementary Table S1). The number of filtered compounds, for each filter, was reported in Scheme 3.

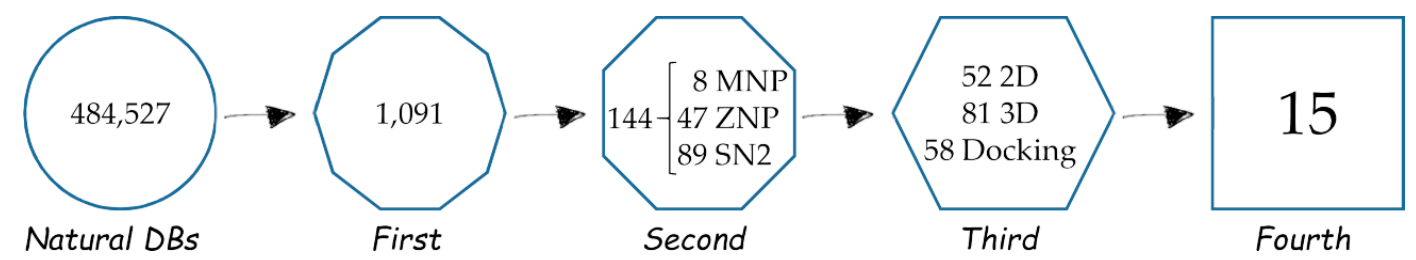

Scheme 3. Application of the fourfold filters described in Scheme 2 to the selected natural databases reporting the number of compounds filtered.

The selected molecules were then also filtered in a third level using a mixed structure and ligand-based approach. The 2D ligand-based filter is based on an HO-1 inhibitor filter returning for each chemical entity a predicted endpoint expressed as $\mathrm{PIC}_{50}$. This 2D-QSAR model was already published [31] and has been built with CORAL software (CORrelation And Logic, version 2016, Istituto di Ricerche Farmacologiche Mario Negri, Milano, Italy) [29,31] employing a Monte Carlo based QSAR analysis [37,38], according to the literature [39-41]. Over 144 compounds, 90 have been defined by the model as outliers; this means that the model does not sufficiently describe their 2D chemical structures. The remaining molecules were returned with a predicted endpoint and indicated as falling within the domain applicability. From this subset, 52 compounds have been predicted to possess $\mathrm{pIC}_{50}$ values between 2.44 and 7.76 .

The same datasets of selected natural products were also evaluated using another ligand-based filter, but this time using 3D descriptors. The 3D molecular structures were aligned to our previous published 3D-QSAR model for the HO-1 receptor [32], and the compounds were then evaluated, as previously reported [42], employing Forge software (v10.4.2, Cresset, New Cambridge House, Hertfordshire, United Kingdom) [43]. Over the whole dataset of natural products, 81 molecules resulted in an excellent or good description by the model. It means that most of the features in the evaluated molecules were well described by the training set of the 3D-QSAR model and the predicted activity can be considered reliable.

The selected molecules were then passed to the structure-based approach adapting the docking procedure already reported for the identification of $\mathrm{HO}-1$ inhibitors $[33,34,44]$. Of the six $\mathrm{HO}-1 /$ ligand co-crystallized structures currently published (PDB IDs: 3K4F, 3CZY, 3TGM, 2DY5, 3HOK, and 6EHA) we discarded the $3 \mathrm{HOK}$ because the pocket present in the so-called northeastern region, dynamically formed only in this X-ray structure, is not correlated with the potency or selectivity for HO-1 isoform. On the contrary, it has been speculated that this pocket could be correlated with the selectivity for the 
HO-2 isoform $[24,45]$. Due to the inherent flexibility of the entire binding site, ranging from $194 \AA^{3}$ (PDB ID 1N45, without ligand) to $585 \AA^{3}$ (PDB ID 3HOK) we choose to use the crystal structure of the HO-1/QC-15 co-crystal (PDB ID 2DY5) in which the cavity is big enough to accommodate different compounds $\left(293 \AA^{3}\right)$ [34]. To validate the docking and considering that in this case it is not possible to use the best docking procedure necessary to correctly accommodate all ligands, i.e., a first roughly docking followed by a Molecular Dynamics and then a re-docking, as reported by us [44], we focalized our attention only to known HO-1 ligands with a potency comparable to that of the co-crystallized QC-15 compound. Therefore, we selected all of the compounds in the HemeOxDB with an experimental HO- $1 \mathrm{IC}_{50}$ value $\leq 5 \mu \mathrm{M}$ and an HO-1/HO-2 selectivity $\geq 30$ (21 compounds) and docking them to evaluate their $K_{\mathrm{i}}$. Although a precise correlation does not exist between the experimental measured $\mathrm{IC}_{50}$ and the calculated $K_{\mathrm{i}}$, the obtained results fall into the same values range suggesting a satisfactory predicting capability of the structure-based method. The docking evaluation of our database has highlighted as many as 58 potential new inhibitors with inhibition values in the range $\mathrm{p} K_{\mathrm{i}} 6.01-8.09$ (1.00-0.01 $\mu \mathrm{M}$, Supplementary Table S2 green highlighted).

All these molecules were selected by the manual inspection of all the docked poses choosing the more reliable, possessing the lowest calculated binding free energy, by means of the classical interaction established by the nitrogen atom of the imidazole ring with the $\mathrm{Fe}^{2+}$ atom of the heme moiety, as depicted in the introduction and noticed in all available HO-1/ligand co-crystallized structures; this feature is shown in Figure 1.

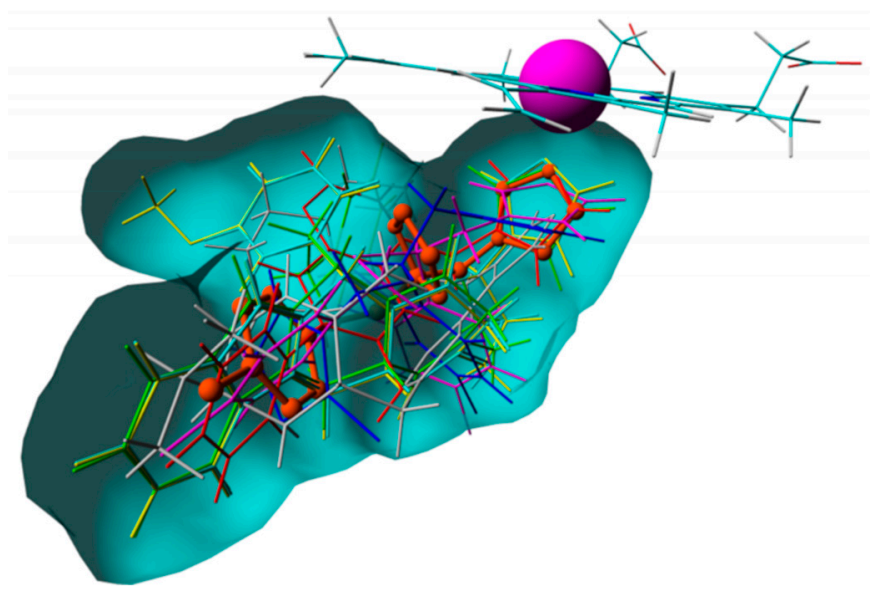

Figure 1. Binding pose of our best compounds (the first seven reported in Table 1) compared with the co-crystallized structure of QC-15 (orange, stick and balls) inside the binding pocket of HO-1 (PDB ID: 2DY5).

\subsection{The Ultimate Fourth Filter}

Finally, to account for all of the obtained results, we further ordered the three datasets according to the mean of the predicted $\mathrm{pIC}_{50}$ and $\mathrm{p} K_{\mathrm{i}}$ values obtained by 2D-QSAR, 3D-QSAR, and docking methodologies. The structures of the best 15 compounds have been reported in Table 1. An accurate literature search for the 15 most promising leads, highlighted that three of them could act as inhibitors of heme-containing enzymes. Notably, molecules SN00001674, SN00005909, and SN00213775 have already been reported as CYP3050A1 [46], Heme Oxygenases [47] and sterol $14 \alpha$-demethylase [48], inhibitors, respectively. It is also worth noting that the calculated average value (6.01, Table 1) of compound SN00005909 (sulconazole) is in excellent agreement with the experimental value $\left(\mathrm{pIC}_{50}=\right.$ 5.96) [47]. 
Table 1. ID, structure, and mean of predicted inhibitory values for the 15 best promising new leads.

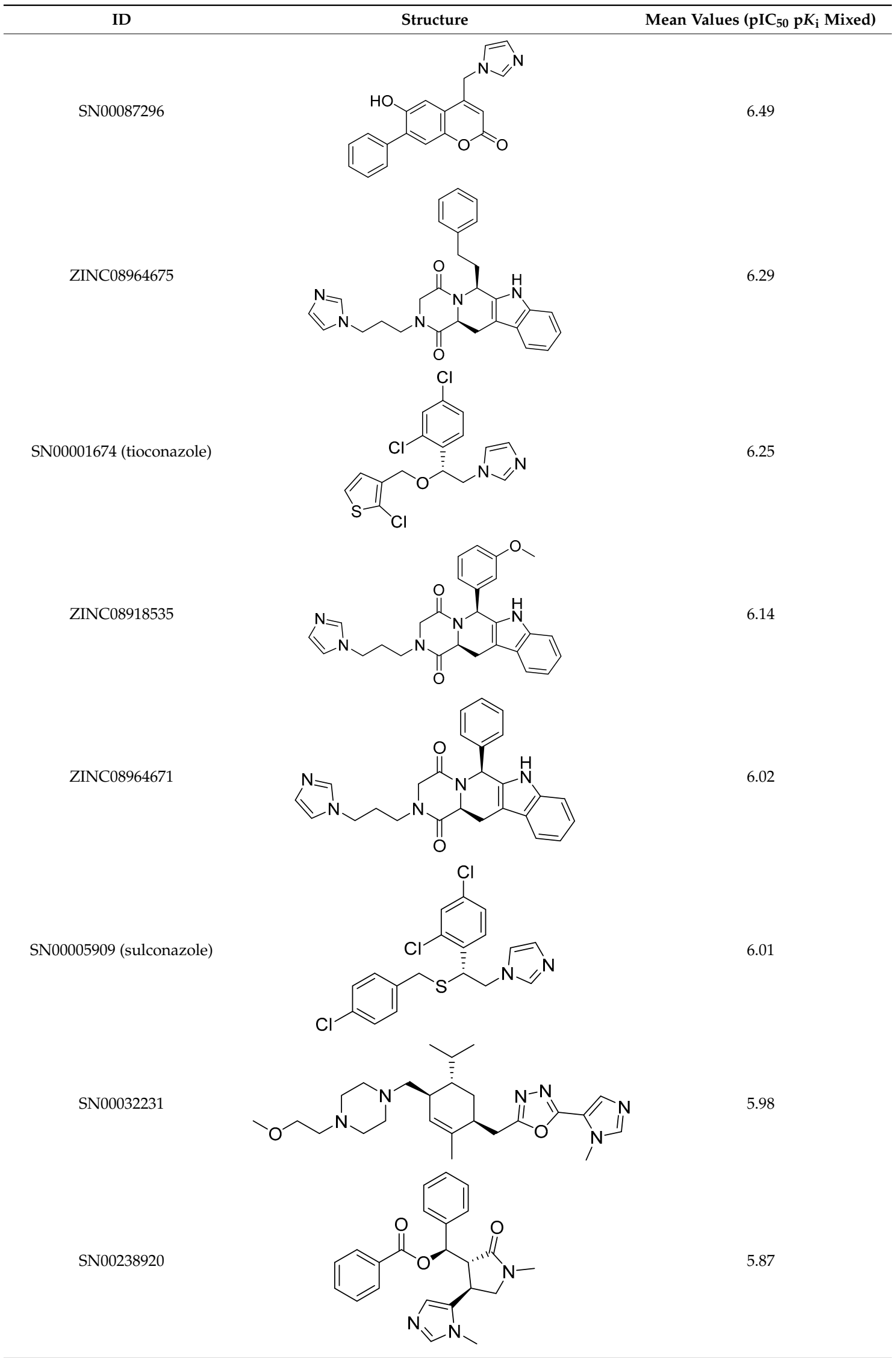


Table 1. Cont.

\begin{tabular}{|c|c|c|}
\hline ID & Structure & Mean Values $\left(\mathrm{pIC}_{50} \mathrm{p} K_{\mathrm{i}}\right.$ Mixed) \\
\hline ZINC03985121 & & 5.85 \\
\hline ZINC08917761 & & 5.83 \\
\hline ZINC03985168 & & 5.78 \\
\hline SN00230416 & & 5.71 \\
\hline SN00032287 & & 5.70 \\
\hline SN00213775 & & 5.67 \\
\hline ZINC03985184 & & 5.65 \\
\hline
\end{tabular}

The docked poses of the best two lead compounds SN00087296 and ZINC08964675 reported in Table 1 have been depicted in Figure 2. From their inspection it is evident that the imidazole ring is involved in the interaction with the iron of the heme, as expected for these types of inhibitors. 


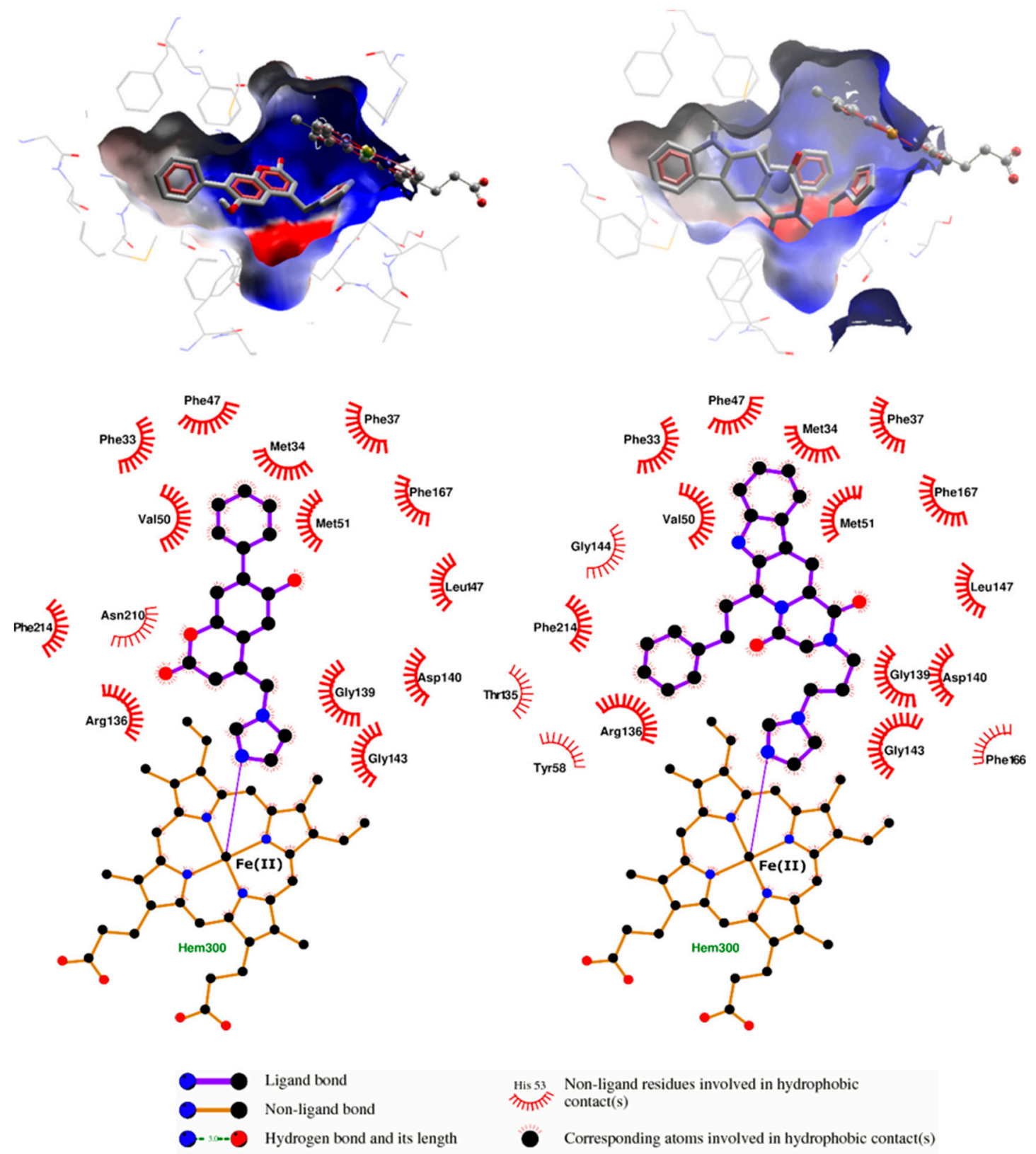

Figure 2. 3D-docked poses (upper) of compounds SN00087296 (left) and ZINC08964675 (right) and respective 2D-ligand/protein interaction diagrams (down); $N$-imidazole-Fe(II)-heme interactions are shown as thin violet lines, while the spoked arcs represent residues making nonbonded contacts with the ligand. 2D diagrams were realized with LigPlot+ software (2.1, EMBL-EBI, Wellcome Genome Campus, Hinxton, Cambridgeshire, United Kingdom) [49].

\subsection{Very Interesting MNP Out of the Statistical/2D Descriptors Filters}

Since none of the eight MNPs residing from the statistical/2D descriptors filters yielded interesting results as an HO- 1 inhibitor, we decided to enlarge the mesh considering, of the remaining 342 compounds that had passed the structural filter, those that satisfied both the Lipinski rule of five and at least seven of the statistical/2D descriptors filters. Four of these last compounds have satisfactorily exceeded the remaining filters (2D-QSAR, 3D-QSAR, and docking; i.e., the ultimate fourth filter) and the obtained results are summarized in Table 2 and Table S3. 
Table 2. ID, structure, and mean of predicted inhibitory values for the four best MNP promising new leads that not strictly satisfied all statistical/2D descriptors filters.

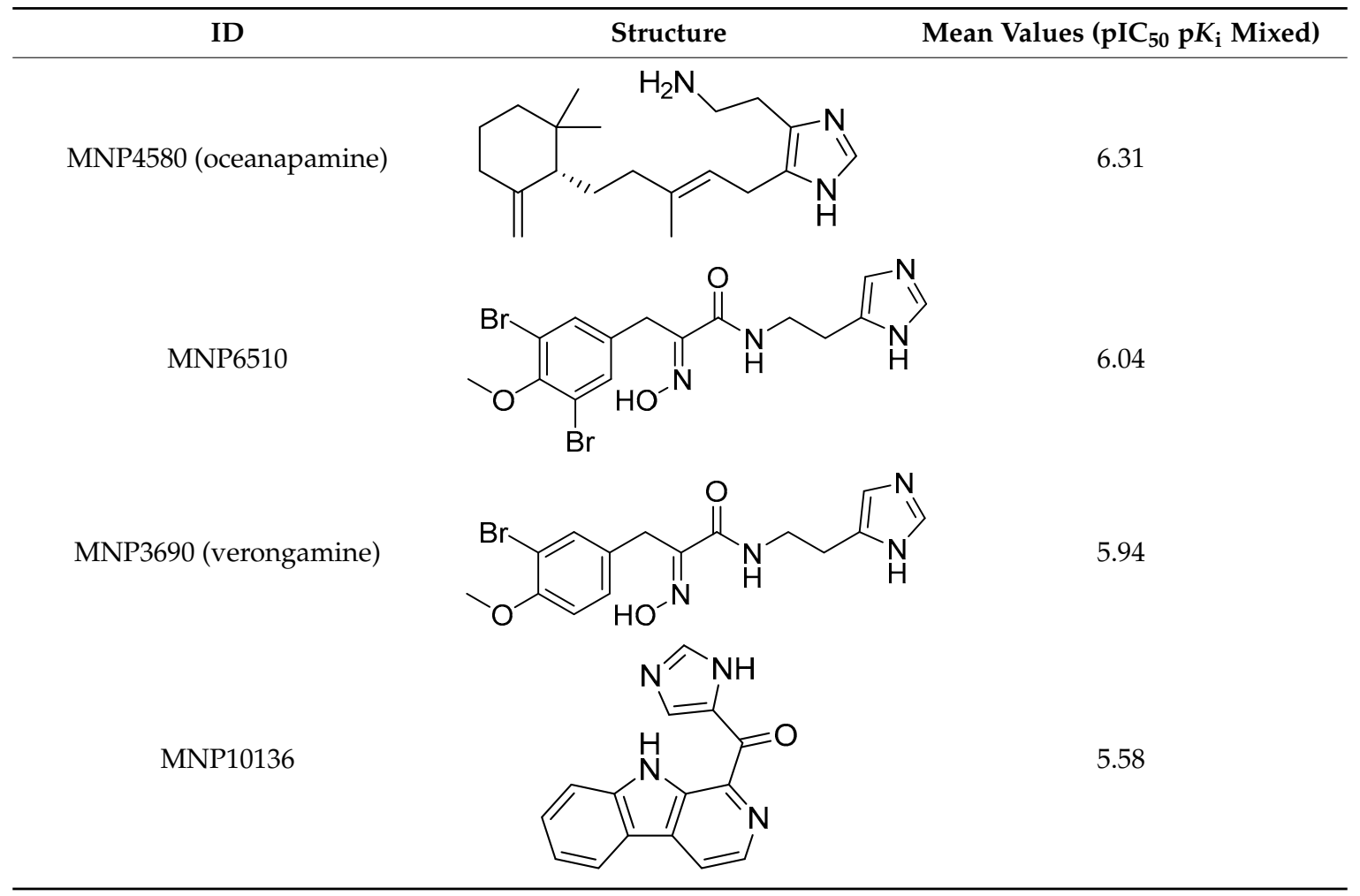

The first compound of Table 2, oceanapamine [50], is an antimicrobial sesquiterpene alkaloid isolated from the Philippine sponge Oceanapia sp., whereas the third compound, verongamine [51], is a histamine $\mathrm{H}_{3}$-antagonist isolated from the marine sponge Verongula gigantea. Since both $\mathrm{HO}-1$ inhibitors and $\mathrm{H}_{3}$-antagonists are implied in the management of the central nervous system (CNS) with diseases such as the Alzheimer [52,53], the verongamine could be a promising starting point to improve the therapeutic management of the latter.

\section{Materials and Methods}

\subsection{Dataset of Compounds}

The chemical structures of the marine and natural dataset were retrieved from Marine Natural Products (MNP, http:/ / docking.umh.es/), ZINC Natural Products (ZNP, http:/ / zinc.docking.org/ browse/catalogs/natural-products) and Super Natural II (SN2, http://bioinf-applied.charite.de/ supernatural_new /index.php) The full list of the 144 molecules that passed the first filter is available as SMILES for external users in the supplementary material (Table S1).

\subsection{Structures $2 D$ to $3 D$ Building and Minimization}

The structures of all the marine and the natural products were built using Marvin Sketch (18.24, ChemAxon Ltd, Budapest, Hungary) [54]. The 2D structures were first subjected to a molecular mechanics energy minimization by the Merck molecular force field (MMFF94) present in Marvin Sketch. The protonation states the molecules were calculated assuming a neutral $\mathrm{pH}$. Before the alignment for the 3D-QSAR filter and for the docking calculation, the geometry of the obtained molecular mechanics 3D structures were further optimized at semi-empirical level using the parameterized model number 3 (PM3) Hamiltonian as implemented in MOPAC package (MOPAC2016 v. 18.151, Stewart Computational Chemistry, Colorado Springs, CO, USA) [55-57]. 


\section{3. $2 D-Q S A R$}

The software CORAL (CORrelation and Logic, version 2016, Istituto di Ricerche Farmacologiche Mario Negri, Milano, Italy) was used for building the 2D-QSAR model using 382 HO-1 inhibitors, as previously reported $[29,31]$. The SMILES strings of the compounds evaluated in this work were converted in order to have a SMILES depiction that was equal to that used for generating the original HO-1 inhibitors model. To each SMILES, a random endpoint value was associated in order for the software to compare this value with the predicted one. The following regression was used for the prediction of the endpoints:

$$
p I C_{50}=0.0000163( \pm 0.0147044)+0.0473151( \pm 0.0001566) \times D C W(0.41)
$$

where DCW is defined as the "descriptor of correlation weights". The regression for the HO-1 pIC $_{50}$ has been developed in a previously published 2D regression model [31].

\subsection{Compound Alignment for the 3D-Ligand Based Filter}

All the 3D semi-empirical derived structures of the selected marine and natural products were imported into the software Forge (v10.4.2, Cresset, New Cambridge House, Hertfordshire, United Kingdom), for the alignment/evaluation of the dataset in the 3D-QSAR model already published [32]. The filed points of each compound (negative, positive, shape and hydrophobic) were calculated and generated using the XED (extended electron distribution) force field in Forge, then the molecules were aligned with the training set of the QSAR model by a maximum common substructure algorithm using a customized and validated set-up [32,58,59]. All the software's parameters used for the conformation hunt and alignment have been presented in the supplementary material (Figures S1 and S2). The maximum number of conformations generated for each molecule was set to 500 . The root-mean-square deviation of atomic positions cutoff, which is the similarity threshold below which two conformers are assumed identical, was set to $0.5 \AA$. The gradient cutoff for conformer minimization was set to $0.1 \mathrm{kcal} / \mathrm{mol}$. The energy window was set to $2.5 \mathrm{kcal} / \mathrm{mol}$, and all the conformers with calculated energy outside the selected energy window were discarded.

\subsection{Molecular Docking}

Docking experiments were performed employing AutoDock software (4.2.5.1, The Scripps Research Institute, San Diego, California Jupiter, FL, USA) implemented in YASARA (v. 18.12.7, YASARA Biosciences GmbH, Vienna, Austria) [60,61] using 2DY5 PDB ID of the HO-1 in complex with QC-15. The maps were generated by the program AutoGrid (4.2.5.1, The Scripps Research Institute, San Diego, California Jupiter, FL, USA) with a spacing of $0.375 \AA$ and dimensions that encompass all atoms extending $5 \AA$ from the surface of the structure of the crystallized ligand. All the parameters were inserted at their default settings. In the docking tab, the macromolecule and ligand are selected, and GA parameters are set as ga_runs $=100$, ga_pop_size $=150$, ga_num_evals $=25000000$, ga_num_generations $=27000$, ga_elitism $=1$, ga_mutation_rate $=0.02$, ga_crossover_rate $=0.8$, ga_crossover_mode $=$ two points, ga_cauchy_alpha $=0.0$, ga_cauchy_beta $=1.0$, number of generations for picking worst individual $=10$.

\section{Conclusions}

In this study, we describe the screening of new potential HO-1 inhibitors reported in a database of 484,577 imidazoles like compounds retrieved from three different databases: Marine Natural Products (MNP), ZINC Natural Products (ZNP) and Super Natural II (SN2). Through a fourfold statistical/computational filtration approach based on 2D descriptors, 2D-QSAR and 3D-QSAR statistical models and docking calculations, different, potentially active imidazole compounds were selected. Among the filtered final compounds some of them demonstrate the capability of heme-containing enzymes inhibition. Interestingly, some of the selected compounds have 
already been used as an antifungal medication and are already FDA approved drugs, particularly tioconazole and sulconazole. The other two, oceanapamine and verongamine, present antibacterial and histamine $\mathrm{H}_{3}$-antagonist activity, respectively. Thus, verongamine, presenting an experimental proved $\mathrm{H}_{3}$-antagonist activity and a potential calculated HO-1 inhibitor activity, could act as a double targeting compound to improve the therapeutic management of the Alzheimer and related CNS diseases. The extension of our findings to the complete list of hit compounds in Tables 1 and 2 can be an avenue worth purchasing for the discovery of novel potent inhibitors of HO-1. Moreover, the natural target of the tioconazole and sulconazole has recently been investigated as off-label in the anticancer chemotherapy [62], and a dual inhibition with HO-1 can be of interest for the field.

Supplementary Materials: The following are available online at http:/ / www.mdpi.com/1660-3397/17/2/113/s1, Figure S1: Forge's parameters used for the conformation hunt. Figure S2: Forge's parameters used for the alignment. Table S1: Dataset of filtered natural products containing a non-fused 2-non-substituted imidazole nucleus. Table S2: Calculated values of $\mathrm{pIC}_{50}(2 \mathrm{D}$ and $3 \mathrm{D}-\mathrm{QSAR})$ and $K_{\mathrm{i}}$ (docking) and their mean. Table S3: Calculated values of pIC50 (2D and 3D-QSAR) and Ki (docking) and their mean for outsider marine compounds.

Author Contributions: Conceptualization, G.F., L.S. and A.R.; Data curation, E.A., V.P. and G.R.; Formal analysis, G.F., D.G. and A.M.; Investigation, G.F., E.A. and A.R.; Methodology, G.F., E.A. and A.R.; Project administration, A.R.; Resources, G.F., D.G., L.R. and A.R.; Supervision, A.R.; Validation, G.F. and E.A.; Writing-original draft, G.F., E.A., V.P., L.S. and A.R.; Writing—review \& editing, G.F., E.A., L.S., G.R., A.M, D.G., V.P. and A.R.

Funding: This research received no external funding.

Acknowledgments: Free academic licenses from ChemAxon and Cresset for their suites of programs are gratefully acknowledged. This work was supported by Research Funding for University (Piano per la Ricerca 2016-2018, project code 57722172107).

Conflicts of Interest: The authors declare no conflict of interest.

\section{References}

1. Tenhunen, R.; Marver, H.S.; Schmid, R. The enzymatic conversion of heme to bilirubin by microsomal heme oxygenase. Proc. Natl. Acad. Sci. USA 1968, 61, 748-755. [CrossRef] [PubMed]

2. Trakshel, G.M.; Kutty, R.K.; Maines, M.D. Purification and characterization of the major constitutive form of testicular heme oxygenase. The noninducible isoform. J. Biol. Chem. 1986, 261, 11131-11137. [PubMed]

3. Abraham, N.G.; Kappas, A. Pharmacological and clinical aspects of heme oxygenase. Pharmacol. Rev. 2008, 60, 79-127. [CrossRef] [PubMed]

4. Battino, M.; Giampieri, F.; Pistollato, F.; Sureda, A.; de Oliveira, M.R.; Pittalà, V.; Fallarino, F.; Nabavi, S.F.; Atanasov, A.G.; Nabavi, S.M. Nrf2 as regulator of innate immunity: A molecular Swiss army knife! Biotechnol. Adv. 2018, 36, 358-370. [CrossRef]

5. Immenschuh, S.; Ramadori, G. Gene regulation of heme oxygenase-1 as a therapeutic target. Biochem. Pharmacol. 2000, 60, 1121-1128. [CrossRef]

6. Pittalà, V.; Vanella, L.; Salerno, L.; Romeo, G.; Marrazzo, A.; Di Giacomo, C.; Sorrenti, V. Effects of polyphenolic derivatives on heme oxygenase-system in metabolic dysfunctions. Curr. Med. Chem. 2018, 25, 1577-1595. [CrossRef] [PubMed]

7. Amata, E.; Pittalà, V.; Marrazzo, A.; Parenti, C.; Prezzavento, O.; Arena, E.; Nabavi, S.M.; Salerno, L. Role of the Nrf2/HO-1 axis in bronchopulmonary dysplasia and hyperoxic lung injuries. Clin. Sci. (Lond.) 2017, 131, 1701-1712. [CrossRef]

8. Pittalà, V.; Sorrenti, V.; Romeo, G.; Acquaviva, A.; Di Giacomo, C.; Salerno, L. Therapeutic potential of Caffeic Acid Phenethyl Ester (CAPE) in diabetes. Curr. Med. Chem. 2016, 25, 4827-4836. [CrossRef]

9. Zhao, H.; Ozen, M.; Wong, R.J.; Stevenson, D.K. Heme oxygenase-1 in pregnancy and cancer: similarities in cellular invasion, cytoprotection, angiogenesis, and immunomodulation. Front. Pharmacol. 2014, 5, 295. [CrossRef]

10. Ayer, A.; Zarjou, A.; Agarwal, A.; Stocker, R. Heme oxygenases in cardiovascular health and disease. Physiol. Rev. 2016, 96, 1449-1508. [CrossRef]

11. Dennery, P.A. Signaling function of heme oxygenase proteins. Antioxid. Redox Signal. 2014, 20, $1743-1753$. [CrossRef] [PubMed] 
12. Jung, N.H.; Kim, H.P.; Kim, B.R.; Cha, S.H.; Kim, G.A.; Ha, H.; Na, Y.E.; Cha, Y.N. Evidence for heme oxygenase-1 association with caveolin-1 and -2 in mouse mesangial cells. IUBMB Life 2003, 55, 525-532. [CrossRef] [PubMed]

13. Slebos, D.J.; Ryter, S.W.; van der Toorn, M.; Liu, F.; Guo, F.; Baty, C.J.; Karlsson, J.M.; Watkins, S.C.; Kim, H.P.; Wang, X.; et al. Mitochondrial localization and function of heme oxygenase- 1 in cigarette smoke-induced cell death. Am. J. Respir. Cell Mol. Biol. 2007, 36, 409-417. [CrossRef] [PubMed]

14. Sacca, P.; Meiss, R.; Casas, G.; Mazza, O.; Calvo, J.C.; Navone, N.; Vazquez, E. Nuclear translocation of haeme oxygenase-1 is associated to prostate cancer. Br. J. Cancer 2007, 97, 1683-1689. [CrossRef] [PubMed]

15. Biswas, C.; Shah, N.; Muthu, M.; La, P.; Fernando, A.P.; Sengupta, S.; Yang, G.; Dennery, P.A. Nuclear heme oxygenase-1 (HO-1) modulates subcellular distribution and activation of Nrf2, impacting metabolic and anti-oxidant defenses. J. Biol. Chem. 2014, 289, 26882-26894. [CrossRef] [PubMed]

16. Loboda, A.; Jozkowicz, A.; Dulak, J. HO-1/CO system in tumor growth, angiogenesis and metabolism-Targeting HO-1 as an anti-tumor therapy. Vascul. Pharmacol. 2015, 74, 11-22. [CrossRef] [PubMed]

17. Salerno, L.; Romeo, G.; Modica, M.N.; Amata, E.; Sorrenti, V.; Barbagallo, I.; Pittalà, V. Heme oxygenase-1: A new druggable target in the management of chronic and acute myeloid leukemia. Eur. J. Med. Chem. 2017, 142, 163-178. [CrossRef]

18. Barbagallo, I.; Giallongo, C.; Volti, G.L.; Distefano, A.; Camiolo, G.; Raffaele, M.; Salerno, L.; Pittalà, V.; Sorrenti, V.; Avola, R.; et al. Heme oxygenase inhibition sensitizes neuroblastoma cells to carfilzomib. Mol. Neurobiol. 2018. [CrossRef]

19. Dichiara, M.; Prezzavento, O.; Marrazzo, A.; Pittalà, V.; Salerno, L.; Rescifina, A.; Amata, E. Recent advances in drug discovery of phototherapeutic non-porphyrinic anticancer agents. Eur. J. Med. Chem. 2017, 142, 459-485. [CrossRef]

20. Chau, L.Y. Heme oxygenase-1: emerging target of cancer therapy. J. Biomed. Sci. 2015, 22, 22. [CrossRef]

21. Pittalà, V.; Vanella, L.; Salerno, L.; Di Giacomo, C.; Acquaviva, R.; Raffaele, M.; Romeo, G.; Modica, M.N.; Prezzavento, O.; Sorrenti, V. Novel Caffeic Acid Phenethyl Ester (Cape) analogues as inducers of heme oxygenase-1. Curr. Pharm. Des. 2017, 23, 2657-2664. [CrossRef] [PubMed]

22. Kirby, R.J.; Divlianska, D.B.; Whig, K.; Bryan, N.; Morfa, C.J.; Koo, A.; Nguyen, K.H.; Maloney, P.; Peddibhotla, S.; Sessions, E.H.; et al. Discovery of novel small-molecule inducers of heme oxygenase-1 that protect human iPSC-derived cardiomyocytes from oxidative stress. J. Pharmacol. Exp. Ther. 2018, 364, 87-96. [CrossRef] [PubMed]

23. Pittalà, V.; Salerno, L.; Romeo, G.; Modica, M.N.; Siracusa, M.A. A focus on heme oxygenase-1 (HO-1) inhibitors. Curr. Med. Chem. 2013, 20, 3711-3732. [CrossRef] [PubMed]

24. Rahman, M.N.; Vukomanovic, D.; Vlahakis, J.Z.; Szarek, W.A.; Nakatsu, K.; Jia, Z. Structural insights into human heme oxygenase- 1 inhibition by potent and selective azole-based compounds. J. R. Soc. Interface 2013, 10. [CrossRef] [PubMed]

25. Sorrenti, V.; Guccione, S.; Di Giacomo, C.; Modica, M.N.; Pittalà, V.; Acquaviva, R.; Basile, L.; Pappalardo, M.; Salerno, L. Evaluation of imidazole-based compounds as heme oxygenase-1 inhibitors. Chem. Biol. Drug Des. 2012, 80, 876-886. [CrossRef] [PubMed]

26. Haegler, P.; Joerin, L.; Krahenbuhl, S.; Bouitbir, J. Hepatocellular toxicity of imidazole and triazole antimycotic agents. Toxicol. Sci. 2017, 157, 183-195. [CrossRef] [PubMed]

27. Roman, G.; Rahman, M.N.; Vukomanovic, D.; Jia, Z.; Nakatsu, K.; Szarek, W.A. Heme oxygenase inhibition by 2-oxy-substituted 1-azolyl-4-phenylbutanes: effect of variation of the azole moiety. X-ray crystal structure of human heme oxygenase-1 in complex with 4-phenyl-1-(1H-1,2,4-triazol-1-yl)-2-butanone. Chem. Biol. Drug Des. 2010, 75, 68-90. [CrossRef]

28. Subashini, G.; Vidhya, K.; Arasakumar, T.; Angayarkanni, J.; Murugesh, E.; Saravanan, A.; Shanmughavel, P.; Mohan, P.S. Quinoline-based imidazole derivative as heme oxygenase-1 inhibitor: A strategy for cancer treatment. Chemistryselect 2018, 3, 3680-3686. [CrossRef]

29. Amata, E.; Marrazzo, A.; Dichiara, M.; Modica, M.N.; Salerno, L.; Prezzavento, O.; Nastasi, G.; Rescifina, A.; Romeo, G.; Pittalà, V. Comprehensive data on a 2D-QSAR model for heme oxygenase isoform 1 inhibitors. Data Brief 2017, 15, 281-299. [CrossRef] 
30. Salerno, L.; Pittalà, V.; Romeo, G.; Modica, M.N.; Siracusa, M.A.; Di Giacomo, C.; Acquaviva, R.; Barbagallo, I.; Tibullo, D.; Sorrenti, V. Evaluation of novel aryloxyalkyl derivatives of imidazole and 1,2,4-triazole as heme oxygenase-1 (HO-1) inhibitors and their antitumor properties. Bioorg. Med. Chem. 2013, 21, 5145-5153. [CrossRef]

31. Amata, E.; Marrazzo, A.; Dichiara, M.; Modica, M.N.; Salerno, L.; Prezzavento, O.; Nastasi, G.; Rescifina, A.; Romeo, G.; Pittalà, V. Heme Oxygenase Database (HemeOxDB) and QSAR analysis of isoform 1 inhibitors. ChemMedChem 2017, 12, 1873-1881. [CrossRef] [PubMed]

32. Floresta, G.; Amata, E.; Dichiara, M.; Marrazzo, A.; Salerno, L.; Romeo, G.; Prezzavento, O.; Pittalà, V.; Rescifina, A. Identification of potentially potent heme oxygenase 1 inhibitors through 3D-QSAR coupled to scaffold-hopping analysis. ChemMedChem 2018, 13, 1336-1342. [CrossRef]

33. Greish, K.F.; Salerno, L.; Al Zahrani, R.; Amata, E.; Modica, M.N.; Romeo, G.; Marrazzo, A.; Prezzavento, O.; Sorrenti, V.; Rescifina, A.; et al. Novel structural insight into inhibitors of heme oxygenase-1 (HO-1) by new imidazole-based compounds: Biochemical and in vitro anticancer activity evaluation. Molecules 2018, 23, 1209. [CrossRef]

34. Salerno, L.; Amata, E.; Romeo, G.; Marrazzo, A.; Prezzavento, O.; Floresta, G.; Sorrenti, V.; Barbagallo, I.; Rescifina, A.; Pittalà, V. Potholing of the hydrophobic heme oxygenase-1 western region for the search of potent and selective imidazole-based inhibitors. Eur. J. Med. Chem. 2018, 148, 54-62. [CrossRef]

35. Floresta, G.; Pittalà, V.; Sorrenti, V.; Romeo, G.; Salerno, L.; Rescifina, A. Development of new HO-1 inhibitors by a thorough scaffold-hopping analysis. Bioorg. Chem. 2018, 81, 334-339. [CrossRef]

36. Sander, T.; Freyss, J.; von Korff, M.; Rufener, C. Datawarrior: An open-source program for chemistry aware data visualization and analysis. J. Chem. Inf. Model. 2015, 55, 460-473. [CrossRef] [PubMed]

37. Toropova, M.A.; Toropov, A.A.; Raska, I., Jr.; Raskova, M. Searching therapeutic agents for treatment of Alzheimer disease using the Monte Carlo method. Comput. Biol. Med. 2015, 64, 148-154. [CrossRef]

38. Toropova, A.P.; Toropov, A.A.; Martyanov, S.E.; Benfenati, E.; Gini, G.; Leszczynska, D.; Leszczynski, J. CORAL: Monte carlo method as a tool for the prediction of the bioconcentration factor of industrial pollutants. Mol. Inform. 2013, 32, 145-154. [CrossRef] [PubMed]

39. Rescifina, A.; Floresta, G.; Marrazzo, A.; Parenti, C.; Prezzavento, O.; Nastasi, G.; Dichiara, M.; Amata, E. Development of a Sigma-2 Receptor affinity filter through a Monte Carlo based QSAR analysis. Eur. J. Pharm. Sci. 2017, 106, 94-101. [CrossRef] [PubMed]

40. Rescifina, A.; Floresta, G.; Marrazzo, A.; Parenti, C.; Prezzavento, O.; Nastasi, G.; Dichiara, M.; Amata, E. Sigma-2 receptor ligands QSAR model dataset. Data Brief 2017, 13, 514-535. [CrossRef] [PubMed]

41. Floresta, G.; Amata, E.; Barbaraci, C.; Gentile, D.; Turnaturi, R.; Marrazzo, A.; Rescifina, A. A structure- and ligand-based virtual screening of a database of "Small" marine natural products for the identification of "Blue" Sigma-2 receptor ligands. Mar. Drugs 2018, 16, 384. [CrossRef]

42. Floresta, G.; Cilibrizzi, A.; Abbate, V.; Spampinato, A.; Zagni, C.; Rescifina, A. 3D-QSAR assisted identification of FABP4 inhibitors: An effective scaffold hopping analysis/QSAR evaluation. Bioorg. Chem. 2019, 84, 276-284. [CrossRef]

43. Cheeseright, T.; Mackey, M.; Rose, S.; Vinter, A. Molecular field extrema as descriptors of biological activity: definition and validation. J. Chem. Inf. Model. 2006, 46, 665-676. [CrossRef]

44. Sorrenti, V.; Pittalà, V.; Romeo, G.; Amata, E.; Dichiara, M.; Marrazzo, A.; Turnaturi, R.; Prezzavento, O.; Barbagallo, I.; Vanella, L.; et al. Targeting heme oxygenase-1 with hybrid compounds to overcome Imatinib resistance in chronic myeloid leukemia cell lines. Eur. J. Med. Chem. 2018, 158, 937-950. [CrossRef]

45. Rahman, M.N.; Vlahakis, J.Z.; Szarek, W.A.; Nakatsu, K.; Jia, Z. X-ray crystal structure of human heme oxygenase-1 in complex with 1-(adamantan-1-yl)-2-(1H-imidazol-1-yl)ethanone: a common binding mode for imidazole-based heme oxygenase-1 inhibitors. J. Med. Chem. 2008, 51, 5943-5952. [CrossRef]

46. Ziniel, P.D.; Karumudi, B.; Barnard, A.H.; Fisher, E.M.; Thatcher, G.R.; Podust, L.M.; Williams, D.L. The schistosoma mansoni cytochrome P450 (CYP3050A1) is essential for worm survival and egg development. PLoS Negl. Trop. Dis. 2015, 9. [CrossRef]

47. Kinobe, R.T.; Dercho, R.A.; Vlahakis, J.Z.; Brien, J.F.; Szarek, W.A.; Nakatsu, K. Inhibition of the enzymatic activity of heme oxygenases by azole-based antifungal drugs. J. Pharmacol. Exp. Ther. 2006, 319, 277-284. [CrossRef]

48. Leroux, P.; Walker, A.S. Multiple mechanisms account for resistance to sterol 14alpha-demethylation inhibitors in field isolates of Mycosphaerella graminicola. Pest Manag. Sci. 2011, 67, 44-59. [CrossRef] 
49. Laskowski, R.A.; Swindells, M.B. LigPlot+: Multiple ligand-protein interaction diagrams for drug discovery. J. Chem. Inf. Model. 2011, 51, 2778-2786. [CrossRef]

50. Boyd, K.G.; Harper, M.K.; Faulkner, D.J. Oceanapamine, a sesquiterpene alkaloid from the Philippine sponge oceanapia sp. J. Nat. Prod. 1995, 58, 302-305. [CrossRef]

51. Mierzwa, R.; King, A.; Conover, M.A.; Tozzi, S.; Puar, M.S.; Patel, M.; Coval, S.J.; Pomponi, S.A. Verongamine, a novel bromotyrosine-derived histamine $\mathrm{H}-3$ antagonist from the marine sponge verongula-gigantea. J. Nat. Prod. 1994, 57, 175-177. [CrossRef]

52. Passani, M.B.; Blandina, P. Histamine receptors in the CNS as targets for therapeutic intervention. Trends Pharmacol. Sci. 2011, 32, 242-249. [CrossRef]

53. Gupta, A.; Lacoste, B.; Pistel, P.J.; Ingram, D.K.; Hamel, E.; Alaoui-Jamali, M.A.; Szarek, W.A.; Vlahakis, J.Z.; Jie, S.; Song, W.; et al. Neurotherapeutic effects of novel HO-1 inhibitors in vitro and in a transgenic mouse model of Alzheimer's disease. J. Neurochem. 2014, 131, 778-790. [CrossRef]

54. Barf, T.; Lehmann, F.; Hammer, K.; Haile, S.; Axen, E.; Medina, C.; Uppenberg, J.; Svensson, S.; Rondahl, L.; Lundback, T. N-Benzyl-indolo carboxylic acids: Design and synthesis of potent and selective adipocyte fatty-acid binding protein (A-FABP) inhibitors. Bioorg. Med. Chem. Lett. 2009, 19, 1745-1748. [CrossRef]

55. Stewart, J.J.P. Optimization of parameters for semiempirical methods IV: Extension of MNDO, AM1, and PM3 to more main group elements. J. Mol. Model. 2004, 10, 155-164. [CrossRef]

56. Alemán, C.; Luque, F.J.; Orozco, M. Suitability of the PM3-derived molecular electrostatic potentials. J. Comput. Chem. 1993, 14, 799-808. [CrossRef]

57. Qiao, F.; Luo, L.; Peng, H.; Luo, S.; Huang, W.; Cui, J.; Li, X.; Kong, L.; Jiang, D.; Chitwood, D.J.; et al. Characterization of three novel fatty acid- and retinoid-binding protein genes (Ha-far-1, Ha-far-2 and Hf-far-1) from the cereal cyst nematodes heterodera avenae and H. filipjevi. PLoS ONE 2016, 11. [CrossRef]

58. Floresta, G.; Rescifina, A.; Marrazzo, A.; Dichiara, M.; Pistarà, V.; Pittalà, V.; Prezzavento, O.; Amata, E. Hyphenated 3D-QSAR statistical model-scaffold hopping analysis for the identification of potentially potent and selective sigma-2 receptor ligands. Eur. J. Med. Chem. 2017, 139, 884-891. [CrossRef]

59. Floresta, G.; Apirakkan, O.; Rescifina, A.; Abbate, V. Discovery of high-affinity cannabinoid receptors ligands through a 3D-QSAR ushered by scaffold-hopping analysis. Molecules 2018, 23, 2183. [CrossRef]

60. Krieger, E.; Vriend, G. YASARA View-molecular graphics for all devices-From smartphones to workstations. Bioinformatics 2014, 30, 2981-2982. [CrossRef]

61. Krieger, E.; Koraimann, G.; Vriend, G. Increasing the precision of comparative models with YASARA NOVA-a self-parameterizing force field. Proteins 2002, 47, 393-402. [CrossRef]

62. Hargrove, T.Y.; Friggeri, L.; Wawrzak, Z.; Sivakumaran, S.; Yazlovitskaya, E.M.; Hiebert, S.W.; Guengerich, F.P.; Waterman, M.R.; Lepesheva, G.I. Human sterol 14alpha-demethylase as a target for anticancer chemotherapy: Towards structure-aided drug design. J. Lipid Res. 2016, 57, 1552-1563. [CrossRef] 